\title{
KEPERCAYAAN DAN MINAT MENGGUNAKAN KEMBALI MERUPAKAN FAKTOR DARI INDUSTRI JASA PENGIRIMAN
}

\author{
Fitrahtul Mutia \\ Universitas Pendidikan Indonesia \\ Fitrahtul.mutia@student.upi.edu \\ Agus Rahayu \\ Universitas Pendidikan Indonesia \\ Agusrahayu@upi.edu \\ Bambang Widjajanta \\ Universitas Pendidikan Indonesia \\ Bambangwidjajanta@upi.edu
}

\begin{abstract}
One of business potential that growing along with the emerge of the internet usage is e-commerce. The development of e-commerce create a dynamic and competitive business competition. Delivery Services Provider become one of the biggest business opportunity that grow in this field, this service become key to determine how good an online transaction is. The trust that consumers give to the company is key to build a good buying environment. This research is propose to discover depiction of users trust on Pos Indonesia Pusat services in Bandung City, discover depiction of repurchase intention trend on users of Pos Indonesia Pusat in Bandung City and to discover the influence of trust to repurchase intention trend on users of Pos Indonesia Pusat in Bandung City. Type of research that used is verified descriptive and explanatory survey as the method with the technique of simple random sampling with sum of the sample is 130 respondent. Technique that used for the data analysis are structural equal model with the assist of a computer software of SPSS AMOS 22.0. Result of this research in general shows a significant influence of trust to repurchase intention trend. The increase the repurchase intention trend, company should make a strategy to leave a good impression on consumers and build a connection with users. Trust as the dominant influencing variabel should be controlled directly by company.
\end{abstract}

Keywords:trust, repurchase intention,

Article Type: Research Paper

\section{PENDAHULUAN}

Minat pembelian ulang merupakan faktor penting setelah terjadinya pergeseran yang signifikan dimana awalnya perusahaan hanya fokus untuk membentuk keputusan pembelian konsumen menjadi bagaimana cara mendorong konsumen agar termotivasi untuk melakukan pembelian berulang ( $\mathrm{Hsu}$, Chang, $\mathrm{Chu}$, \& Lee, 2014). Penilaian konsumen tentang membeli kembali sebuah produk dan jasa yang ditunjuk dari perusahaan yang sama, dengan mempertimbangkan situasi dan keadaan yang baik. Konsumen yang memiliki tingkat kepercayan yang tinggi terhadap perusahaan yang berpengalaman akan lebih mungkin untuk membeli kembali produk dan menggunakan jasa tersebut, daripada konsumen dengan tingkat kepercayaan yang rendah (Hellier et al, 2003).

Perkembangan perdagangan saat ini bukan dalam perdagangan pada industri produk tetapi lebih fokus kepada pelayanan pada industri jasa. Banyak perusahaan penyedia jasa kurir muncul di industri ini yang berusaha memberikan nilai dan kepuasan pelanggan guna memenangkan persaingan (Gale, 1994; Zeithaml et al., 1996; Woodruff, 1997; Parasuraman, 1997 di dalam Wang et al., 2004). Kasus yang terjadi saat ini pada industri jasa kurir terdapatnya masalah kepercayaaan dalam pengiriman produk kepada konsumen yang menyebabkan kerugian pada perusahaan jasa pengiriman barang. Perusahaanperusahaan dunia yang dikenal terbaik di bidang ini adalah United Parcel Supply (UPS), Federal Express (FedEx) dan DHL yang memanfaatkan jadwal produksi just-in-time. Terbukti di Meksiko, Kantor Pos Sepomex di Meksiko mengalami kerugian sebesar $\$ 600$ juta karena adanya pembatasan pengiriman paket dan penyediaan layanan kilat. Lain halnya di China, yang melarang pengiriman ekspres perusahaan secara independen dan perusahaan tersebut harus bergabung dengan perusahaan China dan memiliki saham mayoritas sehingga mengalami 
kerugian pada Pos BUMN di China (Sokol Daniel, 2003).

Pasar e-commerce di Indonesia tumbuh $42 \%$ sejak 2012-2015. Pasar logistik Indonesia tahun 2015 mencapai Rp 2.100 triliun atau tumbuh 14$14,7 \%$ sebagai perbandingan, yang menyamai Anggaran Pendapatan dan Belanja Negara (APBN) 2015, yaitu Rp 2.039,5 triliun (Managing Director 21 Express, Fany Wyadi, 9 September 2015). Menurut Syarifuddin, Direktur Eksekutif Assosiasi Perusahaan Jasa Pengiriman Express Pos dan Logistik Indonesia (Asperindo), potensi bisa melebihi dari kisaran $14 \%$ jika sistem logistik nasional sudah mendukung. Lembaga riset Frost \& Sullivan memperkirakan industri logistik akan tumbuh sebesar 15,4\% menjadi Rp 4,396 triliun pada tahun 2020. Market size saat ini untuk transportasi dan logistik pada 2015 mencapai Rp 2.152 triliun, dengan $\mathrm{Rp}$ 578,9 triliun dari sektor transportasi dan Rp 1.573 triliun dari industri logistik (SWA, 4 Maret 2016). Perusahaan Pos Indonesia mengalami kerugian sebesar $60 \%$.

Sebagai salah satu gambaran luasnya pertumbuhan nilai pasar logistik di Indonesia, Gambar 1.1 menunjukkan market size and growth Pos Indonesia tahun 2005-2014:

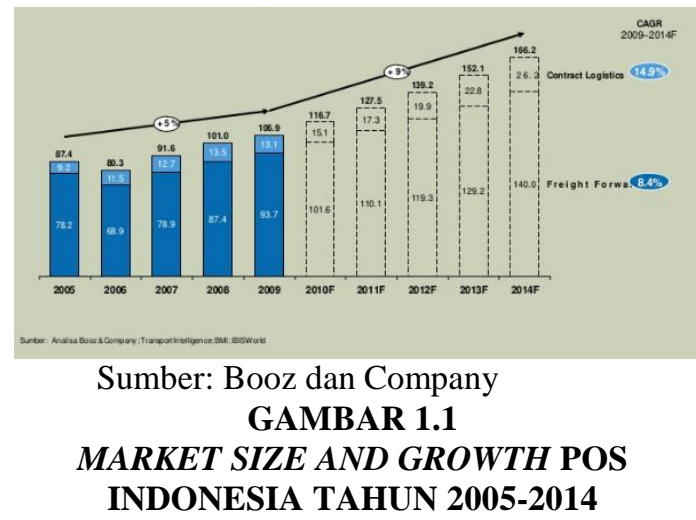

PT Pos Indonesia mengalami persaingan yang kompetitif dengan penyedia jasa kurir lainnya dalam menguasai pasar. Banyak pertimbangan yang dilakukan konsumen sebelum memutuskan untuk menggunakan jasa kurir tersebut (Rangkuti, 2005). Perkembangan jasa kurir di Indonesia saat ini sangat kompetitif untuk menciptakan peluang pasar dan penjualan yang tinggi dengan memberikan kualitas dan pelayanan yang memuaskan konsumen dalam peningkatan pendistribusian yang efisien, harga yang terjangkau dan pelayanan yang optimal. Setiap perusahaan jasa kurir berusaha memberikan yang terbaik kepada konsumen sehingga konsumen tidak ragu dalam memutuskan untuk menggunakan jasa kurir (Supanto, 2011).

Persaingan Pos Indonesia saat ini mengalami penurunan jumlah produksi pengiriman paket. Berdasarkan Tabel 1.1 terlihat bahwa produksi kiriman paket di Pos Indonesia pusat di Kota Bandung cenderung fluktuaktif. Pada jenis pelayanan pos express mengalami penurunan dari tahun ke tahun, paket biasa dalam negeri yang mengalami penurunan jumlah kiriman paket, paket pos kilat khusus juga mengalami fluktuaktif pengiriman, paket pos biasa luar negeri mengalami fluktuaktif dan paket pos udara luar negeri juga mengalami fluktuaktif. Permasalahan ini mengakibatkan rendahnya keputusan konsumen untuk memilih kembali Pos Indonesia, tidak menutup kemungkinan konsumen meninggalkan Pos Indonesia dan beralih kepada perusahaan jasa kurir lainnya. Berikut ini perkembangan data pengiriman paket Pos Indonesia Pusat di Kota Bandung tahun 2013-2015:

TABEL 1.1

DATA KIRIMAN PAKET POS INDONESIA PUSAT DI KOTA BANDUNG TAHUN 2013-2015 KANTOR POS BANDUNG 4000

\begin{tabular}{lccccc}
\hline Tahun & $\begin{array}{c}\text { Pos } \\
\text { Express }\end{array}$ & $\begin{array}{c}\text { Paket } \\
\text { Pos } \\
\text { Biasa }\end{array}$ & $\begin{array}{c}\text { Paket } \\
\text { Kilat } \\
\text { Khusus }\end{array}$ & $\begin{array}{c}\text { Pake } \\
\text { Biasa } \\
\text { Luar } \\
\text { Negeri }\end{array}$ & $\begin{array}{c}\text { Paket } \\
\text { Khusus } \\
\text { Luar } \\
\text { Negeri }\end{array}$ \\
\hline $\mathbf{2 0 1 3}$ & 70.380 & 26.151 & 14.136 & 765 & 1.215 \\
\hline $\mathbf{2 0 1 4}$ & 61.510 & 25.363 & 13.254 & 900 & 1.740 \\
\hline $\mathbf{2 0 1 5}$ & 44.908 & 23.872 & 18.924 & 861 & 1.285 \\
\hline
\end{tabular}

Sumber: Kantor Pos Pusat Kota Bandung (Jl. Asia Afrika No. 49 Bandung)

Sebagai salah satu perusahaan tertua di Indonesia tentunya perusahaan ini mempunyai kepercayaan yang baik di masyarakat. Akan tetapi majunya teknologi informasi berakibat pada melemahnya potensi penjualan produkproduk di Pos Indonesia. Sedangkan untuk jasa pengiriman barang, Pos Indonesia dihadapkan dengan pesaing yang memiliki jangkauan lebih luas, harga kompetitif dan proses yang mudah. Hal ini menjadi masalah untuk Pos Indonesia agar dapat mempertahankan kepercayaan konsumennya (Bejo Lelono, 2012). Kepercayaan dimulai sebelum pihak-pihak tertentu saling mengenal satu sama lain melalui interaksi maupun transaksi (McKnight, D. H., Choudhury, V., \& Kacmar, 2002).

Membangun kepercayaan merupakan salah satu hal utama yang akan dijadikan pertimbangan para calon pengguna jasa untuk menentukan pilihan jasa kurir yang akan dipilihnya. Berikut ini data mengenai Top Brand Index dari beberapa perusahaan jasa kurir yang ada di Indonesia yang dapat dilihat pada Tabel 1.2. Berdasarkan Tabel 1.2 bahwa Pos Indonesia masih lemah dimata konsumen jasa kurir dibandingkan dengan para pesaingnya yaitu Tiki dan JNE yang terus mendominasi dengan nilai persentasi yang sangat jauh berbeda dengan Pos Indonesia. 
TABEL 1.2

TOP BRAND INDEX JASA KURIR DI INDONESIA TAHUN 2011-2015

\begin{tabular}{cccc}
\hline Tahun & TIKI & JNE & $\begin{array}{c}\text { Pos } \\
\text { Indonesia }\end{array}$ \\
\hline 2011 & $70,7 \%$ & $7,9 \%$ & $5,4 \%$ \\
2012 & $56,9 \%$ & $21,2 \%$ & $7,3 \%$ \\
2013 & $53,7 \%$ & $28,6 \%$ & $8,4 \%$ \\
2014 & $45,1 \%$ & $33,2 \%$ & $8,4 \%$ \\
2015 & $43,5 \%$ & $36,2 \%$ & $6,7 \%$ \\
\hline \multicolumn{5}{l}{ Sumber:http://topbrand-award/com/ }
\end{tabular}

Hasil riset yang dilakukan Top Brand Award pada tahun 2011-2015 menemukan bahwa persentase brand index pada Pos Indonesia mengalami fluktuaktif dan penurunan persentase index drastis yang terjadi pada tahun 2014 ke 2015. Dibandingkan dengan pesaingnya TIKI dan JNE, Pos Indonesia mendapatkan persentasi yang masih jauh di bawah. Hal ini menunjukkan lemahnya keputusan menggunakan ulang oleh konsumen dalam menggunakan jasa kurir Pos Indonesia.

Sebagai salah satu gambaran akan luasnya pasar jasa kurir di Indonesia, Tabel 1.3 menunjukkan Indonesia Brand Championship tahun 2015. Terlihat bahwa Pos Indonesia menempati urutan ke 3 dalam kategori Brand Championship dibandingkan dengan TIKI yang menempati urutan pertama dan JNE di urutan kedua. Penilaian indeks berdasarkan jasa pengiriman barang yang paling sering digunakan (pribadi/kantor), jaringan luas, kiriman sampai tepat waktu, terbaik melayani permintaan/keluhan pelanggan, paling aman dan tarif terjangkau.

TABEL 1.3

INDONESIA BRAND CHAMPIONSHIP 2015

\begin{tabular}{ccc}
\hline \multicolumn{2}{c}{$\mathbf{2 0 1 5}$} \\
Type of Award & Company & Index \\
\hline Gold & TIKI & 78,98 \\
Silver & JNE & 77,76 \\
Bronze & Pos Indonesia & 76,37
\end{tabular}

Sumber: the-marketeers.com

Konsumen membuat keputusan pembelian ulang berdasarkan niat pembelian, sedangkan niat tersebut dipengaruhi oleh persepsi, resiko dan kepercayaan. Berdasarkan hal tersebut, maka dapat disimpulkan bahwa kepercayaan konsumen merupakan salah satu solusi untuk meningkatkan keputusan pembelian ulang seseorang baik secara langsung maupun tidak langsung (Kim et al, 2008:548). Bisnis kurir merupakan bisnis kepercayaan (trust) apabila barang atau dokumen yang dititipkan untuk dikirimkan ke tujuannya tidak sampai tepat waktu. Hal tersebut dapat membuat kecewa konsumen dan berakibat akan meninggalkan Pos Indonesia dan memilih jasa kurir lain.

Tujuan penelitian ini adalah: 1) memperoleh temuan mengenai gambaran kepercayaan dan minat menggunakan kembali, 2) memperoleh temuan mengenai pengaruh kepercaayaan terhadap minat menggunakan kembali jasa pengiriman pada Pos Indonesia Pusat di Kota Bandung

\section{KAJIAN PUSTAKA}

Pemasaran merupakan salah satu bagian terpenting dalam keberlangsungan hidup suatu perusahaan. Dalam proses menjalankan strategi pemasaran, perusahaan dituntut untuk dapat memberikan suatu nilai bagi para konsumen untuk membangun hubungan yang baik antara perusahaan dengan konsumen dan menciptakan kepuasan bagi konsumen sehingga dapat meningkatkan penjualan produk secara maksimal. Pemasaran adalah proses dimana perusahaan menciptakan nilai bagi pelanggan dan membangun hubungan yang kuat dengan pelanggan, dengan tujuan menangkap nilai dari pelanggan sebagai imbalannya (Kotler, P., \& Armstrong, 2014a). Salah satu kajian dalam pemasaran adalah perilaku konsumen yang didefinisikan sebagai perilaku menggunakan, mengevaluasi dan menghabiskan produk dan jasa yang konsumen harapkan akan memuaskan kebutuhan konsumen (Schiffman dan Kanuk, 2010:23).

Perilaku konsumen dipengaruhi oleh faktor eksternal dan internal, faktor eksternal terdiri dari cultural dan social factor, sedangkan faktor internal terdiri dari personal dan psychological factor. Faktor psikologi terdiri dari motivasi, persepsi, pembelajaran serta keyakinan/ kepercayaan dan sikap (Kotler, P., \& Armstrong, 2014:159). Kepercayaan dapat diartikan sebagai kerelaan konsumen untuk bergantung pada perusahaan, orang atau merek untuk melaksanakan fungsinya. Kepercayaan dapat mengurangi ketidakpastian atau resiko dan dilihat sebagai proses yang hati-hati, mengingat merek dapat mempengaruhi respons secara seketika (Zikmund, William G., Raymond McLeod Jr., 2003:75).

Membangun sebuah kepercayaan dalam hubungan jangka panjang antara perusahaan dan pelanggan adalah menjadi faktor yang penting untuk menciptakan rasa aman, rasa saling percaya, dan loyalitas. Penjual dituntut untuk dapat membuat pembeli atau konsumen merasa percaya. Begitu pula pada industri jasa kurir. Dengan lebih semakin berkembanganya perusahaan jasa kurir saat ini, perusahaan harus lebih dapat membuat konsumen percaya terhadap 
produk yang dijualnya. Terdapat tiga dimensi dalam membangun kepercayaan yaitu: 1) kemampuan (ability), 2) kebaikan hati (benevolence), dan 3) integritas (integrity) (Mayer, R. C., Davis, J. H., dan Schoorman, 1995).

Umumnya pemasar tertarik untuk menyelidiki pengaruh pemasaran terhadap keputusan pembelian ulang. Berbagai produk telah diteliti dalam konteks ini, diantaranya mencakup berbagai produk seperti otomotif, kamera, peralatan fotografi, jasa restoran, dan jasa broker (Kim, D. J., Ferrin, D. L., \& Rao, 2003). Konsumen cenderung melakukan pembelian kembali untuk produk-produk ternama atau produk dengan merk yang telah dikenal luas terlepas dari apalah produk tersebut berharga mahal atau murah dan apakah produk high involvement atau low involvement (Akir dan Othman, 2010). Penelitian ini diharapkan dapat melengkapi penelitian sebelumnya dengan menyelidiki keputusan pembelian ulang jasa pengiriman barang.

Terdapat beberapa dimensi yang dapat membentuk minat menggunakan kembali/ repurchase intention diantaranya: 1) minat transaksional, 2) niat refrensial, 3) niat preferensial, dan 4) niat eksploratif (Ferdinand, 2002:129).

\section{METODE PENELITIAN}

Penelitian ini dilakukan untuk mengetahui pengaruh kepercayaan terhadap minat menggunakan kembali jasa pengiriman pada pengguna jasa kiriman Pos Indonesia Pusat di Kota Bandung. Variabel bebas (independent variable) atau variabel eksogen yang terdapat pada penelitian ini yaitu kepercayaan dengan dimensi ability, benevolence, dan integrity. sedangkan variabel terikat (dependent variable) atau variabel endogen pada penelitian ini yaitu minat menggunakan kembali dengan dimensi minat transaksional, niat refrensial, niat preferensial, dan niat eksploratif.

Objek/unit analisis pada penelitian ini yaitu pengguna jasa Pos Indonesia Pusat di Kota Bandung. Penelitian ini dilakukan pada kurun waktu kurang dari satu tahun, sehingga teknik pengumpulan data yang digunakan pada penelitian ini adalah cross-sectional method. Teknik yang digunakan dalam penelitian ini adalah teknik propability yaitu simple random dengan jumlah sampel sebanyak 130 responden. Teknik pengumpulan data yang digunakan adalah studi kepustakaan, studi lapangan dengan penyebaran kuesioner, dan studi literatur. Sedangkan teknik analisis data yang dilakukan adalah analisis deskriptif dan verifikatif. Analisis data verifikatif menggunakan SEM dengan bantuan software SMOS 22.0 for windows.

\section{HASIL PENELITIAN DAN PEMBAHASAN}

Pengujian hipotesis penelitian ini dilakukan untuk mengetahui besarnya pengaruh kepercayaan terhadap minat menggunakan kembali. Pengujian hipotesis secara simultan dilakukan menggunakan teknik analisis Structure Equation Model (SEM). Hipotesis penelitian ini adalah kepercayaan berpengaruh secara simultan dan parsial terhadap minat menggunakan kembali. Hipotesis ini diuji secara simultan maupun parsial dengan menggunakan AMOS 22.0 for windows. Hasil pengujian hipotesis secara keseluruhan (simultan) dapat dilihat berdasarkan variabel faktor-faktor kepercayaan memiliki pengaruh langsung terhadap minat menggunakan kembali sebesar 0,844 Secara keseluruhan model konseptual persamaan struktural yang dirancang berdasarkan goodness of fit atau pengujian model penelitian memenuhi kelayakan model (fit) yang berarti sesuai dengan kondisi empiris. maka dapat diambil keputusan bahwa hipotesis nol $\left(\mathrm{H}_{0}\right)$ ditolak dan $\mathrm{H}_{\mathrm{i}}$ diterima, sehingga dapat dikatakan bahwa terdapat hubungan linear antara faktorfaktor pembentuk kepercayaan terhadap minat menggunakan kembali. Hipotesis penelitian dinyatakan diterima, karena sesuai dengan kriteria penerimaan hipotesis yaitu nilai Critical Ratio (C.R.) $\geq 1,99773$ atau nilai probabilitas $(\mathrm{P}) \leq 0,05$ maka $\mathrm{H}_{0}$ ditolak (hipotesis penelitian diterima).

Hasil pengujian secara keseluruhan memberikan hasil yang signifikan. Maka untuk mengetahui dimensi $X$ yang berpengaruh terhadap pembentukan $\mathrm{Y}$, maka dapat dilanjutkan dengan pengujian secara parsial. Dengan membandingkan setiap goodness of fit dengan nilai probability 0,378 , nilai RMSEA $0,024 \leq$ 0,08 , nilai GFI $0,971 \geq 0,90$, nilai AGFI 0,938 $\geq 0,90$, nilai CFI $0,999 \geq 0,90$. Hasil yang diperoleh menunjukkan bahwa semua taksiran parameter pada diagram jalur tersebut adalah signifikan.

Berdasarkan hasil perhitungan diatas, maka dapat digambarkan diagram jalur dari hipotesis pada penelitian sebagai berikut:

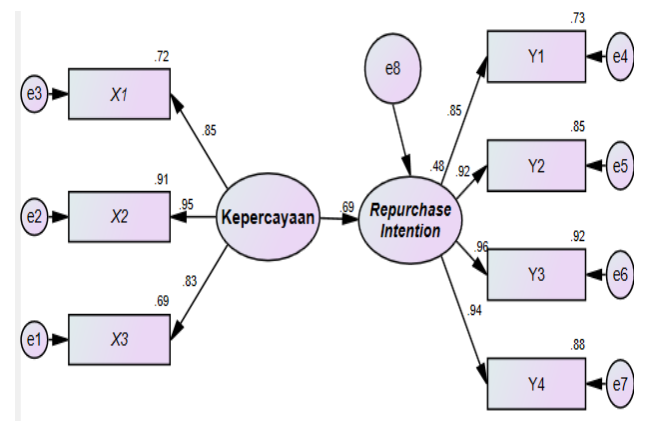


Melalui gambar diagram jalur besarnya pengaruh masing-masing variabel laten secara langsung (standardize direct effect) maupun tidak langsung (standardize indirect effect) serta efek total (standardizes total effect) bahwa variabel faktor-faktor kepercayaan memiliki pengaruh langsung terhadap minat menggunakan kembali sebesar 0.844. Secara keseluruhan model konseptual persamaan struktural yang dirancang berdasarkan goodness of fit atau pengujian model penelitian memenuhi kelayakan model ( fit) yang berarti sesuai dengan kondisi empiris.

Berdasarkan model penelitian, faktor-faktor kepercayaan positif terhadap minat menggunakan kembali dapat dilakukan perhitungan untuk mengetahui pengaruh langsung dan tidak langsung antara dimensi-dimensi. Kepercayaan seseorang tentang produk atau merek akan mempengaruhi keputusan pembelian ulang konsumen. Menentukan keputusan menggunakan jasa yang akan digunakan merupakan hal yang sangat penting karena hal tersebut berdasarkan keyakinan yang berlandaskan kepercayaan (trust) (Taleghani et al., 2011). Konsumen membuat keputusan pembelian ulang berdasarkan niat pembelian, sedangkan niat tersebut dipengaruhi oleh persepsi, resiko dan kepercayaan. Berdasarkan hal tersebut, maka dapat disimpulkan bahwa kepercayaan konsumen merupakan salah satu solusi untuk meningkatkan keputusan pembelian ulang seseorang baik secara langsung maupun tidak langsung (Kim et al, 2008:548). Sedangkan kepercayaan didefenisikan sebagai ketersediaan satu pihak untuk menerima resiko dari tindakan pihak lain berdasarkan harapan bahwa pihak lain akan melakukan tindakan penting untuk pihak yang mempercayainya (Mayer, R. C., Davis, J. H., dan Schoorman, 1995).

Berdasarkan temuan empiris pada penelitian ini menunjukkan bahwa kepercayaan adalah faktor yang menjadi pertimbangan dalam membentuk minat menggunakan ulang. Secara berurutan dimensi yang berpengaruh pada kepercayaan adalah ability, benevolence, dan integrity. Temuan ini berbeda dengan penelitianpenelitian sebelumnya yang hanya menemukan pengaruh saja bukan menemukan dimensi yang berpengaruh lebih signifikan yang membentuk kepercayaan dampaknya terhadap minat menggunakan kembali. Berdasarkan hasil penelitian yang bersifat empiris mengenai kepercayaan, didapat bahwa dimensi integrity memiliki skor yang paling besar.

Temuan empiris pada penelitian ini menunjukkan bahwa minat menggunakan kembali berada pada kategori yang cukup tinggi. Secara berurutan dimensi yang membangun minat menggunakan kembali adalah minat transaksional, niat refrensial, niat preferensial, dan niat eksploratif. Berdasarkan hasil penelitian diperoleh total pengaruh langsung kepercayaan terhadap minat menggunakan kembali sebesar 0,844 atau $(0,844 \times 100 \%) 84,4 \%$, Hal ini dikatakan bahwa terdapat hubungan saling pengaruh yang positif dan signifikan antara kedua variabel. Berdasarkan hasil tersebut, dapat diketahui bahwa kepercayaan berpengaruh terhadap minat menggunakan kembali jasa Pos Indonesia Pusat di Kota Bandung.

Berdasarkan uraian teori dan hasil penelitian yang telah dilakukan menggunakan analisis deskriptif dan verifikatif dengan menggunakan structural equation model (SEM) antara dimensi kepercayaan terhadap minat menggunakan kembali. Kepercayaan memiliki pengaruh yang positif terhadap minat menggunakan kembali jasa Pos Indonesia Pusat di Kota Bandung dengan nilai pengaruh langsung sebesar 0,844 atau $84.4 \%$, hasil ini diperoleh melalui uji model pada structural equation model melalui AMOS versi 22,0.

Dimensi yang membentuk kepercayaan memiliki pengaruh yang positif terhadap minat menggunakan kembali jasa Pos Indonesia Pusat di Kota Bandung. Dengan nilai masing-masing dimensi yaitu: 1) ability sebesar 0.830, 2) benevolence sebesar $0.954,3$ ) integrity sebesar 0.874 hasil ini diperoleh melalui uji model pada structural equation model melalui AMOS versi 22,0.

Penelitian ini diharapkan dapat membantu bagi Pos Indonesia Pusat di Kota Bandung dapat meningkatkan minat menggunakan kembali melalui strategi kepercayaan.

\section{DAFTAR PUSTAKA}

Ferdinand, A. (2002). No Title. Structural Equation Modelling Dalam Penelitian Manajemen, 129.

Hellier, P. K., M, G. G., A, C. R., \& R. J. A. (2003). No Title. Customer Repurchase Intention: A General Structural Equation Model, (Europan Journal of Marketing), 1762-1800.

Hsu, M.-H., Chang, C.-M., Chu, K.-K., \& Lee, Y.-J. (2014). Determinants of Repurchase Intention in Online Group-Buying: The Perspectives of Delone \& Mclean IS Success Model And Trust. Computers in Human Behavior, 36(1), 234-245.

Kim, D. J., Ferrin, D. L., \& Rao, H. R. (2003). No Title. Antecedents of Consumer Trust in Bto-C Electronic Commerce, Preceeding of Ninth Americas Conference on Information System, 157-167.

Kim, H. S. (2008). No Title. Culture and the 
Cognitive and Neuroendocrine Responses to Speech, 94, 32-47.

Kotler, P., \& Armstrong, G. (2014a). No Title. In Principles of Marketing (14th ed.) (p. 27).

Kotler, P., \& Armstrong, G. (2014b). No Title. In Principles of Marketing (14th ed.) (p. 159).

Mayer, R. C., Davis, J. H., dan Schoorman, F. D. (1995). No Title. An Integrative Model of Organizational Trust, 20, 709-734.

McKnight, D. H., Choudhury, V., \& Kacmar, C. (2002). No Title. Developing and Validating Trust Measures for ECommerce: An Integrative Typology, 13(3), 334-359.

Rangkuti, F. (2005). No Title. In Marketing Made Easy.

Schiffman, L. G. L. L. K. (2010). No Title. In Consumer Behavior, New Jersey (p. 23).

Sokol, D. (2003). No Title. The Rule of Reason and the Goals of Antitrust.

Taleghani, M., Branch, R., Gilaninia, S., Branch, R., Mousavian, S. J., \& Branch, R. (2011). The Role of Relationship Marketing in Customer Orientation Process in the Banking Industry with focus on Loyalty Department of Industrial Management, 2(19), 155-166.

Wang., E. T. G. (2004). No Title. An Integrated Franework of Customer Value and Customer Relationship Management Performance: A Customer-Based Perspective from China.

Zikmund, William G., Raymond McLeod Jr., and F. W. G. (2003). No Title. Customer Relationship Management: Intergrating Marketing Strategy and Information Techonology. 